Universidad de Lima

Facultad de Comunicación

Carrera de Comunicación

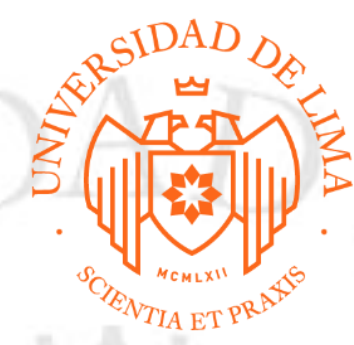

\title{
EL USO DE ANIMALES EN UNA PRODUCCIÓN AUDIOVISUAL, UNA MIRADA ÉTICA Y LEGAL
}

Trabajo de investigación para optar el grado de Bachiller en Comunicación

\section{Labrín Mesía, Loretta Mayeli}

Código 20142895

Soto Sarmiento, Susan Amparo código

Código 20133204

Lima - Perú

Abril de 2019 


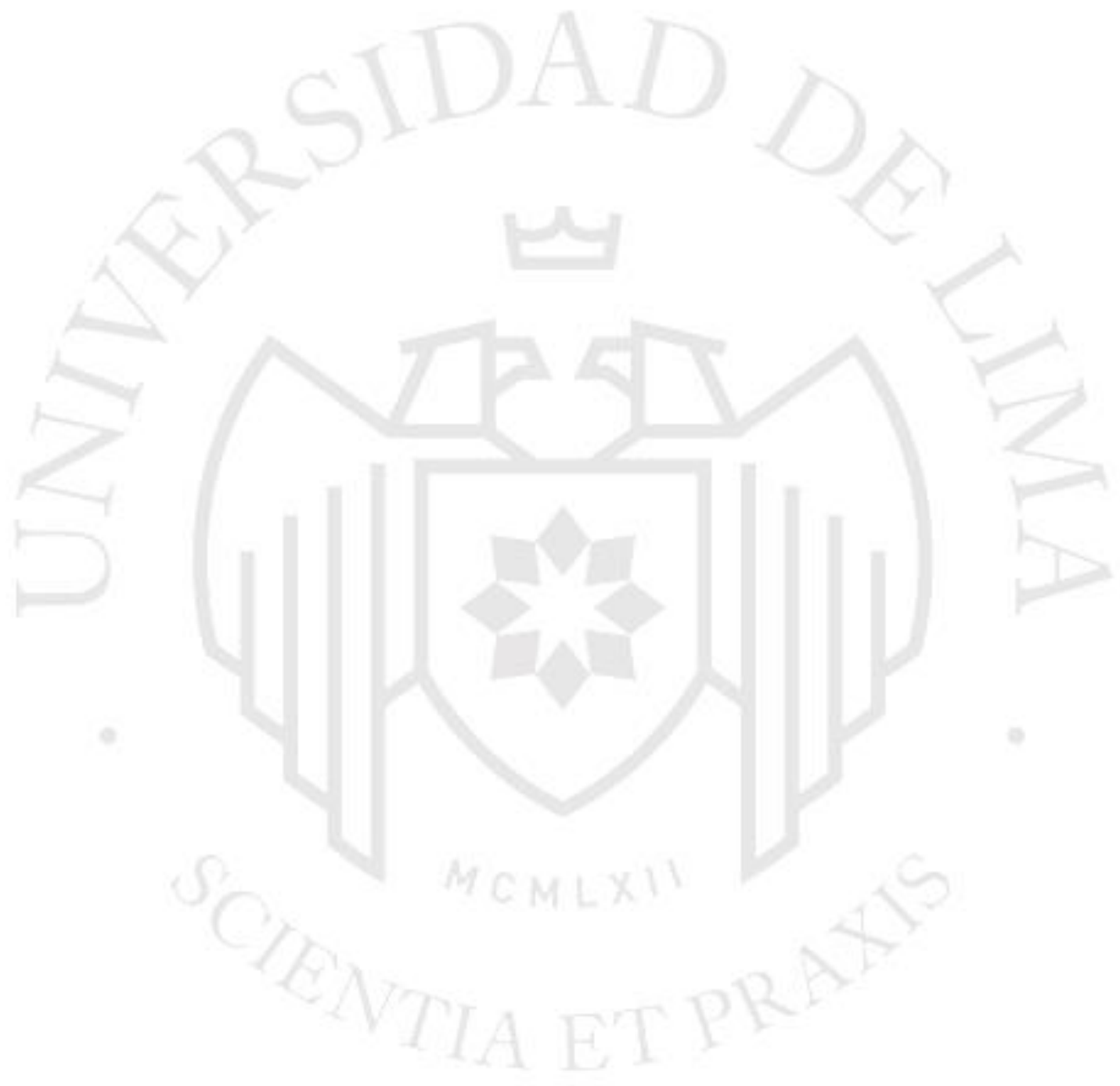




\section{EL USO DE ANIMALES EN UNA PRODUCCIÓN AUDIOVISUAL, UNA MIRADA ÉTICA Y LEGAL}




\section{TABLA DE CONTENIDO}

\section{INTRODUCCIÓN.........................................................................................6}

CAPÍTULO I: METODOLOGÍA ......................................................8

CAPÍTULO II: RESULTADOS ........................................................9

2.1 Perspectivas sobre obligaciones morales con los animales ......9

2.2 Perspectivas éticas frente a los animales .................................10

2.3 Leyes sobre animales ............................................................. 12

2.3.1Derecho de Bienestar Animal ..................................................... 13

2.3.2Derechos de los animales (Animal Rights) .............................13

2.4 Comparación de la legislación de Estados Unidos con el Reino

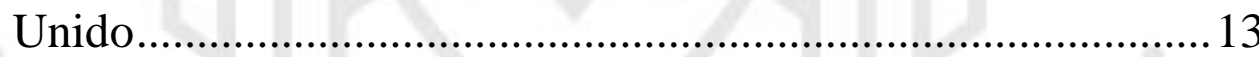

2.5 Ley de Protección Animal en el Perú ........................................15

2.6 Análisis de casos de maltrato animal...........................................16

CAPÍTULO III: DISCUSIÓN .............................................................20

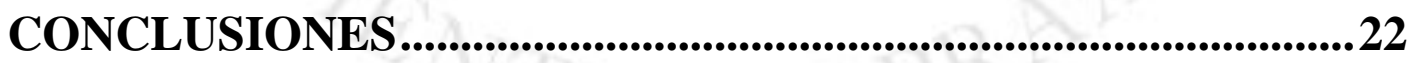

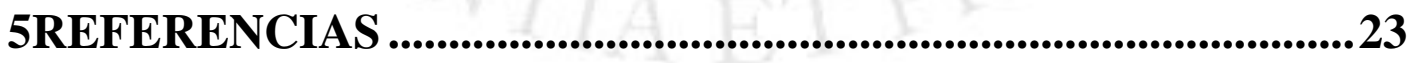

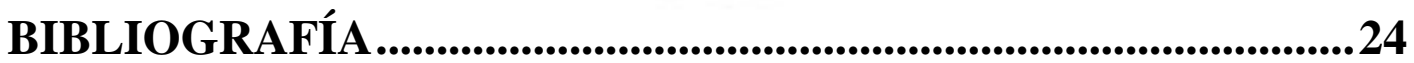




\section{ÍNDICE DE ANEXOS}

Anexo 1: Entrevistas

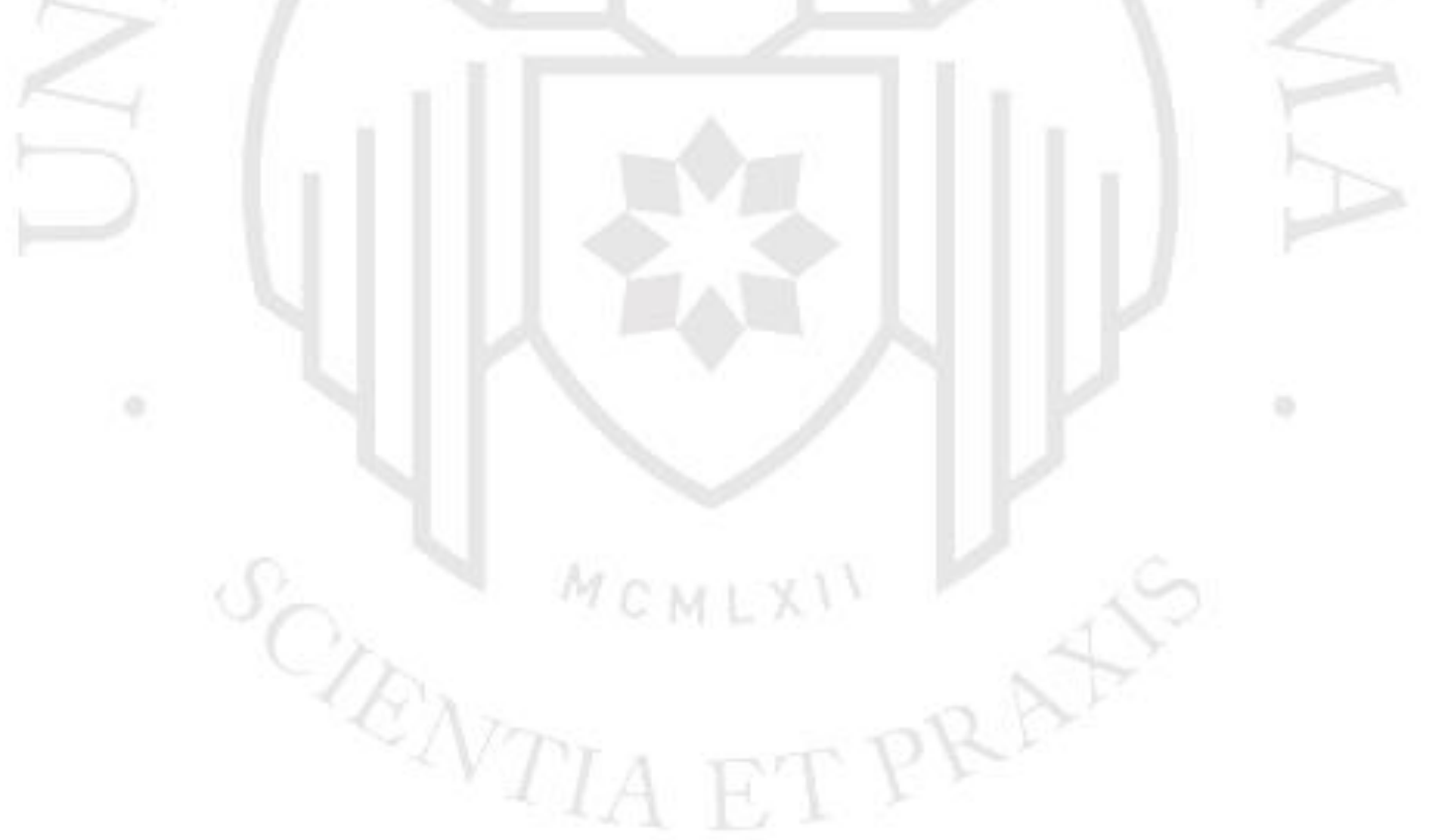




\section{INTRODUCCIÓN}

Hoy en día la mayoría de las personas siente afecto por los animales. Todos, salvo algunos pocos, compartimos la noción de que no es correcto maltratar a un animal, ya sea causándole dolor o muerte, simplemente porque nos da placer, nos divierte, nos conviene o porque estamos acostumbrados a hacerlo.

Sin embargo, en pleno siglo XXI, teniendo a nuestra disposición un sinfín de herramientas tecnológicas mucho más éticas; el hecho de usar un animal para el entretenimiento es una práctica completamente innecesaria, cruel e injusta, que aún se realiza. Esta atenta contra la integridad de este ser, puesto que al ser objetificado, es privado de su libertad e incluso es ridiculizado.

Es importante recalcar que un rodaje con animales no empieza y termina en unas horas de actuación. Sino que implica preparación, entrenamiento, viajes, aislamiento y muchas veces, lamentablemente, maltrato. No siempre es fácil apreciar el sufrimiento de un animal en pantalla. Muchas veces parece gozar de buena salud e incluso puede parecer contento.

La verdadera problemática es, a menudo, invisible a primera vista, por eso la importancia de poner fin a estas prácticas, impulsando el reconocimiento de la crueldad innecesaria que es ejercida a un ser que merece los mismos derechos, pero por sobre todo respeto, por parte del público y del sector audiovisual para que se pueda avanzar hacia un mundo más empático.

Es por esta razón que la presente investigación tiene como propósito tres objetivos centrales:

- Analizar si el uso de los animales para el entretenimiento es una práctica ética. 
- Conocer cuáles son las leyes que amparan y/o protegen los derechos de los animales.

- Determinar en qué casos el uso de un animal en una producción audiovisual es considerado como maltrato.

\section{Pregunta de investigación}

¿Es ético y legal el uso de animales para la realización de un producto audiovisual? 


\section{CAPÍTULO I: METODOLOGÍA}

Para el presente trabajo se han consultado distintas fuentes, entre artículos académicos, periodísticos y tesis sobre ética y legislación relacionada al uso de los animales. Se han revisado las diferentes posturas éticas que existen en torno a este tema y las leyes que han sido promulgadas a favor de los animales (Estados Unidos, Reino Unido y Perú).

Por otro lado, se realizaron entrevistas a dos expertos para conocer su postura ética y legal respecto al uso de animales en el entretenimiento. Víctor Krebs, doctor en Filosofía por la Universidad de Notre Dame, Estados Unidos y profesor del Centro de Estudios Filosóficos de la Pontificia Universidad Católica del Perú, y el Dr. Pierre Foy, abogado y profesor de la PUCP especialista en derecho ambiental y animalístico.

Finalmente, se analizaron casos sobre el maltrato animal en películas de Hollywood y una serie de televisión peruana. 


\section{CAPÍTULO II: RESULTADOS}

\subsection{Perspectivas sobre obligaciones morales con los animales}

La perspectiva antropocéntrica argumenta que las personas solo tienen deberes indirectos con los animales, es decir, es erróneo asignarles derechos morales a los animales porque estos solo se limitan a ser propiedad de los seres humanos. Arellano y T.Hall (2012) indican que no tenemos obligaciones hacia un ser que no tiene conciencia moral porque no tienen razón, lenguaje, ni experimentan empatía. Por lo tanto, no debemos ninguna consideración moral hacia ellos.

Asimismo, como expone otro enfoque antropocéntrico, al demostrar que la ética es un contrato social, los animales están excluidos de este.

No obstante, puesto que el contrato social es algo implícito en la interacción social, no hay razón para excluir, por ejemplo, a los animales domésticos o trabajadores. Creemos que una familia puede tener un contrato implícito con su perro o su gato, por tanto, el perro tiene que comportarse bien a cambio de recibir alimentación y alojamiento (Arellano \& T. Hall, 2012, pág. 89).

A su vez, Kant, 1997 (citado por Arellano \& T. Hall, 2012) defendió la noción de persona como el único ser que implica derechos morales y obligaciones directas, e indica que el trato a los animales es un deber no a los animales en sí mismo, sino en consideración a nuestra propia dignidad, y por eso un deber indirecto: "Uno debe practicar amabilidad cariñosa hacia los animales, puesto que quién muestra crueldad a los animales se pone duro también en sus relaciones para con seres humanos." (Kant, 1997, citado por Arellano \& T. Hall, 2012). El hecho que sea animal no significa que te obliga a maltratarlo o faltarle el respeto, supone una falta de humanidad y disminuye la dignidad de la persona. Según Kant (1997), los que actúan bien con los animales tienen consideración a su propia dignidad. Existe un dicho que dice: "Quien trata mal a un animal no es buen natural". 
La segunda perspectiva de Nussbaum, 2012 (citado por Arellano \& T. Hall, 2012) se basa en el desarrollo de las capacidades propias de los animales, enfocada en el concepto de "florecimiento", el cual es "el derecho moral de cada especie para lograr su plenitud: para ejercer funciones que corresponden a la naturaleza de la especie”. Por ejemplo: caballos de carrera, perros de carrera o caza, gallos de pelea, perros circenses que muestran condiciones naturales para el adiestramiento. Respecto a ello, "los seres humanos tienen una obligación de justicia al respetar y empoderar las capacidades de los animales" (Arellano \& T. Hall, 2012: 90)

\subsection{Perspectivas éticas frente a los animales}

Las principales perspectivas que reconocen el valor moral a los animales son la biocéntrica (valoración de todas las formas de vida), la zoocéntrica (valoración de los animales) y la sensocéntrica (valoración de los seres sensibles). "La primera de ellas puede representarse por la ecología profunda y otorga valor moral a todos los seres vivos y naturaleza" (Soutullo, 2012, pág. 5); mientras que la segunda, excluye a las plantas y microorganismos, y la sensocéntrica solamente adjudica valor moral a los animales que tienen la capacidad de sentir. Es en la segunda mitad del siglo XVIII, que el filósofo utilitarista Jeremy Bentham, reflexiona sobre el reconocimiento del valor moral de los animales; sin embargo, recién en la segunda mitad del siglo XX, aparece un auténtico movimiento que defiende a los animales.

Por su parte, Peter Singer, en su libro Liberación Animal, defiende la igualdad de derechos de los animales. Este principio básico de igualdad no exige tratamiento igual o idéntico; exige igual consideración para las personas como animales.

Sugiere que "habiendo aceptado el principio de igualdad como base moral sólida para las relaciones con otros miembros de nuestra propia especie, igualmente nos comprometemos a aceptarlo como base moral sólida para las relaciones con los que no pertenecen a ella: los animales no humanos." Singer (2000). 
Es decir, al igual que el racismo, para Singer, discriminar por motivos de especie animal, se llama “especieísmo".

Respecto a la posición de defensa de los animales, Bentham (utilitarista moderno) argumenta: "La cuestión no es si los animales ¿pueden razonar?, ni tampoco: ¿pueden hablar?, sino: ¿pueden sentir el sufrimiento”. Lo que conlleva a Singer (2000) afirmar que: "Si un ser sufre, no puede existir ningún tipo de justificación moral para rechazar que ese sufrimiento sea tenido en cuenta".

De esta manera, Singer concluye que "el dolor y el sufrimiento son malos y deberían ser evitados o minimizados, independientemente de la raza, el sexo, o la especie del ser que sufra".

En Gran Bretaña (1951), tres comités gubernamentales independientes de expertos sobre materias relativas a los animales concluyeron:

...creemos que la evidencia fisiológica y particularmente anatómica justifica y refuerza completamente la creencia basada en el sentido común de que los animales sienten dolor (Singer, 2000).

Al contrario, Tom Regan optó por un enfoque distinto a la de Singer. En su libro “Animal Rights", defiende los derechos de los animales, refuta y se opone a las posturas morales de los autores anteriores (doctrina antropológica, kantismo y utilitarismo), considerándolas incorrectas.

Reagan respalda principalmente, que es inaceptable la perspectiva de los humanos frente a los animales, donde estos se convierten en simples recursos a nuestro servicio. Indica que "existen animales que pueden experimentar una vida interior compleja con independencia de los intereses de otros. En consecuencia, en tales casos, los animales reciben la denominación de sujetos de una vida" (Giménez Candela \& Lao Rodríguez, 2010, pág. 8).

El ser "sujetos de una vida", aplica a todas las especies de animales y no admite jerarquías. Por ello, “este autor persigue, sobre todo la abolición del uso de los animales en la ciencia, el abandono total de la ganadería animal comercial, la 
supresión de la caza y captura comercial o deportiva" (Giménez Candela \& Lao Rodríguez, 2010, pág. 8).

Por otro lado, Garyl Francione, considerado una institución en el marco del derecho de los animales y autor de "Animals Property and The Law" (1995), indica que es erróneo considerar a los animales como parte de nuestra propiedad. Por consiguiente, mientras se mantengan bajo esta, no presumen interese morales significativos y prevalecerá el derecho de las personas sobre los animales.

De forma similar, Francione considera que las leyes sobre el derecho de los animales en ningún caso pretenden cambiar su estatus, aunque busquen evitar el sufrimiento innecesario, los animales seguirán siendo considerado cosas mientras no se modifique su tratamiento como propiedad. Es decir, mientras los animales sean objetos de propiedad, no serán libres ni gozarán de los derechos morales como el respeto y la consideración.

\subsection{Leyes sobre animales}

El 15 de octubre de 1978 fue proclamada la Declaración Universal de Derechos del animal por la UNESCO y posteriormente por la ONU ${ }^{1}$.

Esta declaración proclama que todos los animales nacen iguales y tienen derecho a la existencia, respeto, atención, cuidados y protección del hombre. Debe ser tomada como punto de partida de cada legislación estatal. Por ello, Lao (2010) analiza la regulación jurídica de Estados Unidos y Reino Unido, pioneras sobre las leyes del derecho animal.

\footnotetext{
${ }^{1}$ Preámbulo Declaración Universal de los Derechos del Animal: Considerando que todo animal posee derechos. Considerando que el desconocimiento y el desprecio de dichos derechos han conducido y siguen conduciendo al hombre a cometer crímenes contra la naturaleza y contra los animales. Considerando que el reconocimiento por parte de la especie humana de los derechos a la existencia de las otras especies de animales constituye el fundamento de la coexistencia de las especies en el mundo. Considerando que el hombre comete genocidio y existe la amenaza de que siga cometiéndolo. Considerando que el respeto hacia los animales por el hombre está ligado al respeto de los hombres entre ellos mismos. Y considerando que la educación debe enseñar desde la infancia a observar, comprender y amar a los animales. Ver ley completa en (Fundación Affinity.org, s.f.)
} 


\subsubsection{Derecho de Bienestar Animal}

Mediante la norma se busca eliminar cualquier sufrimiento innecesario hacia los animales y mejorar su vida. Según Giménez \& Lao (2010), el derecho de bienestar animal "acepta que los animales son utilizados por los hombres y trata de mejorar su suerte"

Los que defienden esta posición, consideran que los animales merecen consideración moral porque pueden sentir sufrimiento y no por si tienen capacidad para razonar.

Este derecho al bienestar de los animales

"se sitúa en el marco del utilitarismo, es decir, que la vida se rige por los intereses de unos y otros, y que lo que hay que tomar específicamente en consideración, es la suma de los intereses en juego de los individuos que participan en una acción determinada. De un lado los intereses individuales de los seres humanos y de otro los de los animales" (Giménez Candela \& Lao Rodríguez, 2010).

\subsubsection{Derechos de los animales (Animal Rights)}

Esta teoría, defendida por Tom Regan, parte de la premisa de que los animales merecen consideración moral por ser sujetos de vida. No acepta que se priorice evitar el sufrimiento animal, sino erradicar su explotación como recurso.

"Los defensores de esta teoría abogan por la no-utilización de los animales y por el hecho de atribuir derechos a los mamíferos superiores, que ostentan capacidad para razonar, planificar el futuro, poseen abstracción mental y empatía con otros animales, algunas veces distintos de su especie" (Giménez Candela \& Lao Rodríguez, 2010).

\subsection{Comparación de la legislación de Estados Unidos con el Reino Unido}

En los Estados Unidos, a nivel federal, la ley de mayor importancia sobre la protección animal es la Ley de Bienestar Animal (Animal Welfare Act), firmada en 1967 y dirigida principalmente a los animales de laboratorio. Al mismo tiempo, la razón por la que el movimiento de Bienestar Animal se considera 
estadounidense se debe a que "fue el único país que propuso modificar el estatus de "propiedad" que ostentan los animales con respecto a los seres humanos. Mediante este cambio, las personas son sus guardianes y no dueños" (Giménez Candela \& Lao Rodríguez, 2010).

En primera instancia, el ámbito de aplicación de esta ley se reducía a los animales domésticos, primates u otros animales mamíferos, excluyéndose aves y roedores, que fueron incluidos en años posteriores.

De la misma manera, en la legislación del Reino Unido (Animal Welfare Act 2006), no se protege a todos los animales, sino que por el contrario se atribuye una protección exclusiva a animales mamíferos (incluso en un grado más reducido) y se excluye a los invertebrados. Esta ley establece que "constituye una ofensa someter a sufrimiento innecesario un animal- a través de un acto de comisión, omisión o bien siendo el propietario, permitiendo un acto de comisión u omisión” (Giménez Candela \& Lao Rodríguez, 2010, pág. 12).

Esta afirmación además implica que existe una relación de propiedad entre el dueño y animal.

Las diferencias esenciales entre estas dos leyes radican en la amplitud de la protección. El Animal Welfare Act de los Estados Unidos es magistral y abarca aspectos variados que garantizan el Derecho de Bienestar Animal. Se establece una regulación para eliminar el uso de animales robados, las condiciones mínimas de bienestar en que se debe mantener a los animales domésticos, regula los procedimientos que se deben de seguir para la utilización de animales en el marco de la experimentación científica, así como la creación de Comités para el ejercicio de inspecciones que controlen el cumplimiento de la normativa, determinación de las condiciones mínimas para el transporte de los animales, entre otras.

Al contrario, el ámbito de aplicación del Animal Welfare Act 2006 del Reino Unido, insiste en eliminar exclusivamente la crueldad infligida sobre los animales y no prevenirla, buscando así su bienestar total. 


\subsection{Ley de Protección Animal en el Perú}

La ley $N^{\circ} 30407$ de Protección y Bienestar del animal en el Perú, firmada en el 2016

“establece las condiciones necesarias para brindar protección a especies de animales vertebrados domésticos o silvestres y reconocerlos como animales sensibles, los cuales merecen gozar de buen trato por parte del ser humano y vivir en armonía con su medio ambiente" (Congreso de la República del Perú, 2016) .

Siendo el objetivo de la ley (artículo 3):

"Proteger la vida y salud de los animales, impedir el maltrato y la crueldad, causados directa o indirectamente por el ser humano, que les ocasiona un sufrimiento innecesario, lesión o muerte. Así como fomentar el respeto a la vida y el bienestar de los animales a través de la educación. Además, de velar por su bienestar para prevenir accidentes a sus poblaciones y aquellas enfermedades transmisibles al ser humano.

Así como promover la participación de las entidades públicas y privadas y de todos los actores sociales involucrados, con sujeción al ordenamiento constitucional y legal.”. (Congreso de la República del Perú, 2016)

De esta manera se prohíbe toda práctica que pueda atentar contra su protección y bienestar como: abandono de animales en la vía pública, su utilización en espectáculos de entretenimiento público o privado donde se obligue o condicione a realizar actividades que no sean compatibles con su comportamiento natural o se afecte su integridad física, experimentación y caza de vertebrados acuáticos.

La presente ley incorpora el artículo 206-A al Código Penal (2016), donde indica que "la persona que comete actos de crueldad o abandono contra un animal doméstico o silvestre es reprimido con pena privativa de libertad no mayor de tres años, con cien a ciento ochenta días de multa y con inhabilitación 
de conformidad con el numeral 13 del artículo 36 (incapacidad definitiva o temporal para la tenencia de animales)".

Asimismo, la ley $\mathrm{N}^{\circ} 30407$, señala que toda persona natural o jurídica está facultada para denunciar casos de crueldad hacia los animales. Sin embargo, no se especifica el procedimiento sobre la recepción de denuncias.

Cabe señalar que la ley no es específica para casos de utilización de los animales en la producción audiovisual.

\subsection{Análisis de casos de maltrato animal}

El maltrato animal en la industria del entretenimiento, especialmente en Hollywood, es una situación que ocurre desde hace muchos años. Es una práctica sigilosa a pesar de que el American Humane Association Film (AHA) se encarga de supervisar las grandes producciones y obliga a las productoras colocar al final de la película "Ningún animal ha sido dañado en este filme".

Los animales en las películas o series de televisión muchas veces se convierten en elementos importantes para la historia o en algunos casos son el personaje principal. Este trabajo tan delicado, que puede vulnerar los derechos de los animales requiere que Hollywood trabaje junto con la AHA, quienes velan por la seguridad de los animales.

La AHA se asoció con el Sindicato de actores de Estados Unidos (Screen Actor Guilds), obligando a los cineastas a ponerse en contacto con ellos antes de que cualquier animal esté presente en el set, luego de que en el año de 1980 se registraran una serie de actividades inhumanas contra los animales en la película western Heaven's Gate.

A continuación, se analizarán dos casos sobre maltrato animal en Hollywood y un caso ocurrido en Perú:

Primer caso: La Razón de Estar Contigo (2017) 
La película narra la historia de un perro que encuentra el significado de su existencia a través de su relación con los humanos, reencarnándose en diversas razas de perro en varias ocasiones para enseñarle a sus amos la importancia de amar.

Lo controversial de esta película se dio cuando fechas próximas al rodaje, el sitio web de entretenimiento Thirty-mile zone (TMZ)², sacó a la luz un vídeo del maltrato de uno de los perros durante la filmación. Un pastor alemán era arrojado al agua contra su voluntad, por parte del entrenador.

Se tiene registrado que $\mathrm{AHA}^{3}$ no se pronunció al respecto, a pesar de haber estado a cargo de la supervisión del rodaje.

Sin embargo, este acto fue inmediatamente sancionado por la entidad animalista PETA $^{4}$ con el fin de evitar el estreno de la película, la cual se produjo con total normalidad. Aunque este filme obtuvo una baja calificación por parte de la crítica cinematográfica.

Esto es sólo una muestra de cómo muchas veces se hace caso omiso del sufrimiento innecesario que se le puede causar a un animal, en contraste con lo propuesto por los autores anteriormente y bajo la legislación de Estados Unidos (Animal Welfare Act) que persigue eliminar mediante la regulación, todo sufrimiento innecesario en el proceso de utilización de los animales involucrados.

Este suceso, debió haber llegado más allá de solamente la repercusión por parte de los medios, y de este modo consolidar una sanción a los productores para que se eviten casos similares en el futuro.

\footnotetext{
${ }^{2}$ Ver video en https://www.youtube.com/watch?v=csLiYr5OGbg

${ }^{3}$ American Humane Association (AHA)

${ }^{4}$ People for the Ethical Treatment of Animals (PETA)
} 
Segundo caso: El Hobbit, un viaje inesperado (2011)

Gracias a una investigación realizada por la revista de entretenimiento estadounidense, The Hollywood Reporter ${ }^{5}$, se pudo conocer el caso de 27 animales que murieron por deshidratación, agotamiento e incluso ahogados durante un alto del rodaje de El Hobbit, película rodada en Nueva Zelanda.

Cuando el entrenador de la filmación, John Smythe, denunció la muerte de los animales, la asociación le dijo que no valía la pena abrir una investigación por falta de pruebas. Así mismo la AHA, no asumió cargos porque alegó que debido a que los hechos no ocurrieron durante el rodaje, no realizarían ninguna intervención; por otro lado, se hizo referencia de que los animales que mueren por negligencia, falta de cuidados $\mathrm{o}$ de medidas protectoras no son responsabilidad de la productora ni de la asociación. Dando como conclusión en su informe que "habiendo monitorizado todos los eventos significativos con relación a animales", consideraban que "ningún animal había sido perjudicado durante la acción" (Associated Press, 2012).

Por el lado del sistema legal tampoco se pudo realizar ninguna acción, ya que Animal Welfare, es excluyente y especeísta al momento de realizar inspecciones que cumplan la mínima de condiciones aptas para preservar animales, puesto que sólo se reduce a la protección de algunos mamíferos como perros y gatos. Sin embargo, en esta grabación se arremetió contra la vida de diferentes animales como gallinas, ovejas, cabras, entre otros.

\section{Caso peruano: Yuru, la princesa amazónica (2007)}

Esta producción ${ }^{6}$ tenía como temática la defensa de especies de animales para proteger la diversidad de la selva Amazónica Peruana, donde se escenificaba la lucha de una jovencita contra la caza furtiva. Situación que se vivía y está

\footnotetext{
5 Wranglers: "The Hobbit" Production Responsible for up to 27 Animal Deaths. Ver investigación completa en: https://www.hollywoodreporter.com/news/hobbit-animal-deaths-wranglers-blame-392010

${ }^{6}$ Ver tráiler de la serie en https://www.youtube.com/watch?v=x017M_Y5GO4
} 
presente hasta hoy en día en el Perú; sin embargo, la producción de la serie incurrió en una controversia no investigada a fondo por las autoridades.

Cabe resaltar que a pesar de que al inicio de la serie se emitía un comunicado explicando que ninguna especie fue maltratada y que todas pertenecían a un zoocriadero; es bueno hacer un llamado a la conciencia y considerar que en realidad dichos zoocriaderos, tienen un sistema de funcionamiento igual al de los zoológicos, pues los animales viven en cautiverio, pero se "les da un mejor trato". Hecho que no justifica el daño que se realiza contra la biodiversidad al sacar una especie de su hábitat original para ser llevado a otro entorno, en este caso el protagonista era el mono choro de cola amarilla, una especie protegida en peligro de extinción. 


\section{CAPÍTULO III: DISCUSIÓN}

El filósofo Víctor Krebs, profesor principal del Departamento de Humanidades en la Pontificia Universidad Católica del Perú, y el abogado Pierre Foy (PUCP) coinciden con que la postura bienestarista es una herramienta que persigue eliminar mediante la regulación, todo sufrimiento innecesario en el proceso de utilización de los animales involucrados.

Se debe reconocer el valor de los animales por sí mismos, y no por la utilidad que dan al ser humano.

Pierre Foy indica que el bienestarismo es una solución transicional de la ley a medida que la sociedad tenga una mayor conciencia por el respeto de los animales.

Según Víctor Krebs, debe existir una visión menos antropocéntrica y más ecológica donde se eliminen las jerarquías que consideran a las personas como únicos poseedores del valor moral, donde los seres humanos le conceden esa "ciudadanía" a los animales por extensión.

Como se ha visto en los casos analizados y en contraste con lo recopilado por The Hollywod Reporter, alrededor del 99,98\% de las películas que se ruedan en la industria de Hollywood obtienen su sello de garantía por organizaciones como la AHA que no necesariamente se hacen responsables del proceso de rodaje.

Se puede afirmar que a simple vista no es fácil apreciar si un animal ha sido maltratado para la elaboración de una producción audiovisual, porque lo que apreciamos en la pantalla es el producto final, es importante tomar en cuenta que detrás de todo esto existen múltiples factores como: la procedencia de los animales (muchos han sido capturados o nacidos en cautiverio), las condiciones en que viven y los métodos de entrenamiento en los que se les somete para actuar (estrés de los traslados, mutilaciones, fomento indirecto del tráfico de los animales). 
Según nuestra apreciación, el uso de los animales para el entretenimiento en la mayoría de los casos comprende la objetificación de estos, y es considerado un maltrato porque se arrebata al animal de su hábitat natural convirtiéndolo en un prisionero. Lo cual es completamente inmoral e incorrecto éticamente.

Sin embargo, al igual que Víctor Krebs, consideramos que pueden existir ciertas excepciones, el animal puede participar en una producción siempre y cuando sea tratado con respeto y no se atente contra su naturaleza e integridad. Pero someterlos a nuestra necesidad, con el fin de crear una situación a su costa, con fines lucrativos muestra una actitud de propiedad de los seres humanos con los animales. 


\section{CONCLUSIONES}

Como se observa en los casos analizados y en contraste con la información recopilada, muchas veces el lado legislativo no satisface al momento de emitir sanciones, entonces lo que debería prevalecer es la ética, además de emitir leyes que sancionen a los productores que hagan uso de animales en sus producciones audiovisuales. Se debería aplicar una currícula en la formación de los profesionales orientados al área audiovisual especialmente destinada a la concientización de la importancia del respeto hacia los animales y su no objetificación para el entretenimiento.

Como indican Víctor Krebs y Tom Regan, lo que se necesita en la actualidad no es un mejor trato a los animales mediante políticas bienestaristas sino la abolición total del maltrato animal, entendiéndolo como la esclavitud y objetificación de los mismos. Los animales no deben considerarse como una propiedad del ser humano, sino como un ser con un valor intrínseco.

A medida que la sociedad se va sensibilizando cada vez más con los animales, y considerando que hoy en día se cuenta con un avance tecnológico (Computergenerated imagenary- $\mathrm{CGI}^{7}$ ) que puede sustituir el uso de los animales en contra de su voluntad, queda claro que el cambio debe empezar por todas las personas, ya sea por parte de la audiencia que consume dichas producciones como por los miembros del sector cinematográfico que se encargan de la elaboración de estos; que reconozcan la crueldad de esta práctica innecesaria y que decidan que ha llegado el momento de avanzar hacia un mundo más empático y respetuoso.

${ }^{7}$ CGI: es un tipo de tecnología informática que se utiliza para realizar efectos especiales en el cine y en la televisión. CGI es una abreviatura de imágenes generadas por computadora. (Collins Dictionary of English, 2019) 


\section{REFERENCIAS}

Arellano, J., \& T. Hall, R. (2012). Bioética de la Biotecnología. (1). Santiago de Querétaro: Fontamara. Recuperado el 2017, de http://unidadbioetica.com/libros/Bio\%C3\%A9tica-de-laBiotecnolog\%C3\%ADa.pdf

Associated Press. (19 de Noviembre de 2012). The Hollywood Reporter. Recuperado el Noviembre de 2017, de https://www.hollywoodreporter.com/news/hobbitanimal-deaths-wranglers-blame-392010

Collins Dictionary of English. (2019). Collins Dictionary. Recuperado el abril de 2019, de https://www.collinsdictionary.com/dictionary/english/cgi

Congreso de la República del Perú. (6 de enero de 2016). El Peruano. Recuperado el 12 de noviembre de 2017, de http://busquedas.elperuano.pe/normaslegales/ley-deproteccion-y-bienestar-animal-ley-n-30407-1331474-1/

Cruz Espinoza, P. (30 de enero de 2016). Seamos Legales. Recuperado el 25 de noviembre de 2017, de http://blog.pucp.edu.pe/blog/seamoslegales/2016/01/30/mi-mascota-y-elderecho/

FAADA. (2014). Los Animales No Venden. 11/2017, de Fundación para el Asesoramiento y Acción de Defensa de los Animales Sitio web: http://adnimalsfree.org/documentos/Adnimalsfree-dossier-Z-6-PIXART.pdf

Fundación Affinity.org. (s.f.). Fundación Affinity. Obtenido de https://www.fundacionaffinity.org/sites/default/files/derechos_animal.pdf

Giménez Candela, T., \& Lao Rodríguez, B. (2010). Legislación Inglesa y Norteamericana: Derecho Animal. (U. A. Policy), Ed.) Barcelona, España. Recuperado el 15 noviembre del 2017

Jone Bouman. (2013). Animalswereharmed. 2017, de The Hollywood Reporter Sitio web: https://www.hollywoodreporter.com/feature/

Kant, I. (1997). Lectures on Ethics (The Cambridge Edition of the Works of Immanuel Kant) (P. Heath \& J. Schneewind, Eds.). Cambridge: Cambridge University Press. doi:10.1017/CBO9781107049512

Lao Rodríguez, B. (2010). Michigan State University. Recuperado el octubre de 2017, de https://www.animallaw.info/article/legislaci\%C3\%B3n-inglesa-ynorteamericana-derecho-animal-0

Nussbaum, M. (2012). Las Fronteras de la Justicia. Barcelona: Paidos Iberica. Recuperado el febrero de 2019

P.R. (2017). Película La Razón de estar contigo. 2017, de La Tercera Sitio web: http://www.latercera.com/noticia/pelicula-la-razon-estar-contigo-enfrentapolemica-maltrato-animal/

Salvador Arellano, J. (s.f.). Ética y animales. Obtenido de http://www.derechoanimal.info/images/pdf/Etica-y-animales.pdf

Singer, P. (2000). Una vida ética escritos. Madrid: Aguilar, Altea, Taurus, Alfaguara, S.A. Recuperado el 12 de noviembre del 2017 


\section{BIBLIOGRAFÍA}

Baum, G. (25 de Noviembre de 2013). The Hollywood Reporter. Recuperado el Noviembre de 2017, de https://www.hollywoodreporter.com/news/animalswere-harmed-hollywood-reporter-investigation-on-set-injury-death-cover-ups659556

Del Barrio Producciones. (2007). Del Barrio Producciones. Recuperado el Noviembre de 2017, de http://www.delbarrio.pe/yuru-la-princesa-amazonica/

Emilio Vargas. (2017). La razón de estar contigo. 2017, de Kopodo Sitio web: http://www.kopodo.com/2017/la-razon-de-estar-contigo-a-dogs-purpose-critica/

Emol. (19 de enero de 2017). Emol. Espectáculos. Recuperado el 15 de noviembre de 2017 ,

de

http://www.emol.com/noticias/Espectaculos/2017/01/19/840836/Maltratoanimal-en-Hollywood-Una-practica-silenciosa-y-comun-en-la-industria.html

Instituto Pacífico. (8 de enero de 2016). Instituto Pacífico. Recuperado el 25 de noviembre de 2017, de http://boletines.actualidadpenal.com.pe/resena-de-lasprincipales-normas-penales-y-procesales-penales-y-penitenciarias-publicadasla-ultima-semana/derecho-penal-parte-especial/se-modifica-el-codigo-penalmediante-la-ley-n30407-noticia-551.html

Marta Peirano. (2013). Ningún animal sufrió daños durante el rodaje (salvo los que murieron a golpes, ahogados o empalados). 2017, de Eldiario.es Sitio web: http://www.eldiario.es/cultura/cine/Ningun_animal_sufrio_danos_rodaje_0_202 980370.html

Soutullo, D. (2012). El valor moral de los animales y su bienestar. (P. Abierta, Ed.) España. Recuperado el marzo de 2019, de https://zadoco.site/el-valor-moral-delos-animales-y-su-bienestar.html 


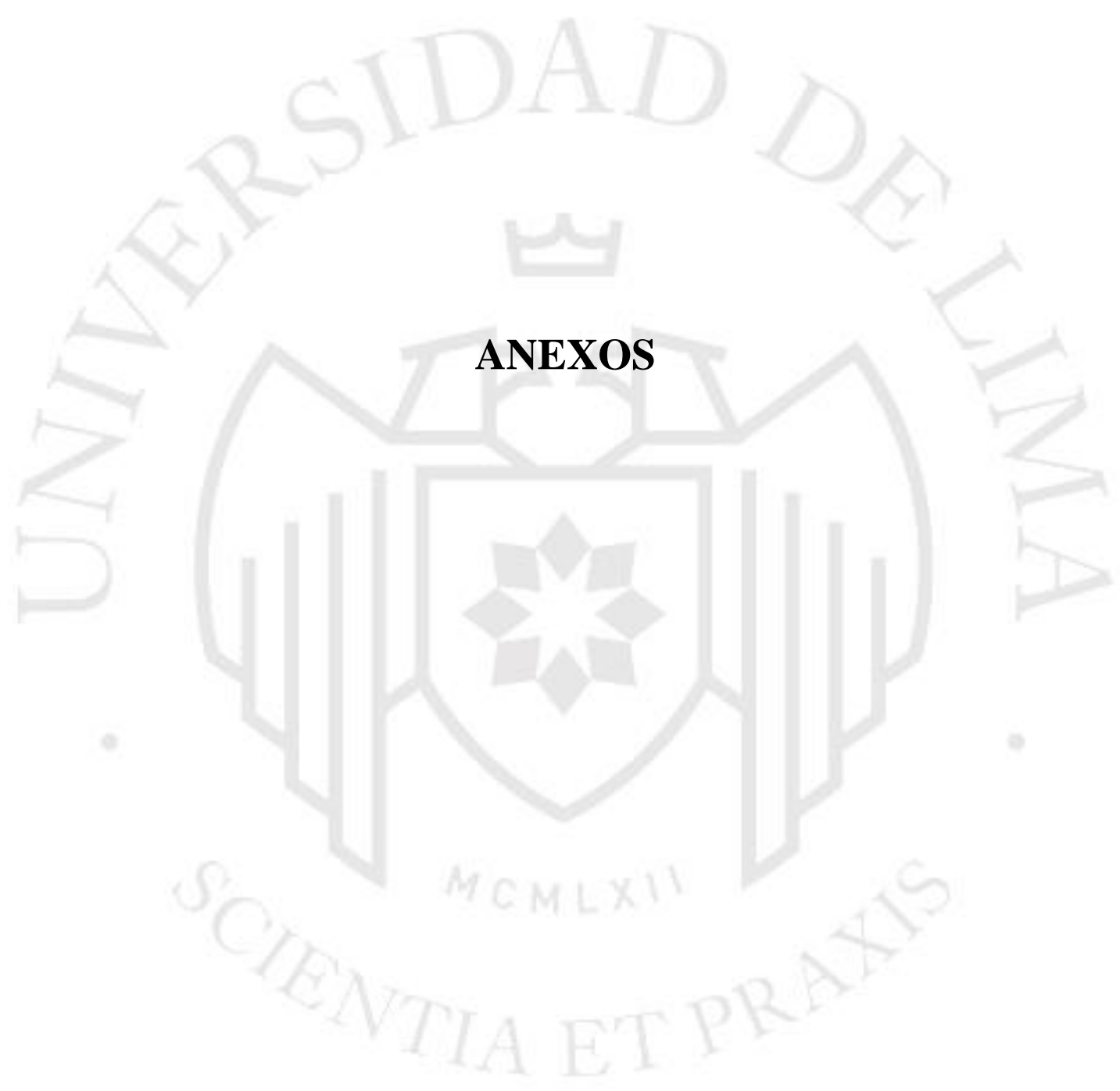




\section{Anexo 1: Entrevistas}

Ver respuestas de las entrevistas realizadas a los especialistas sobre el tema en el cuadro comparativo a continuación:

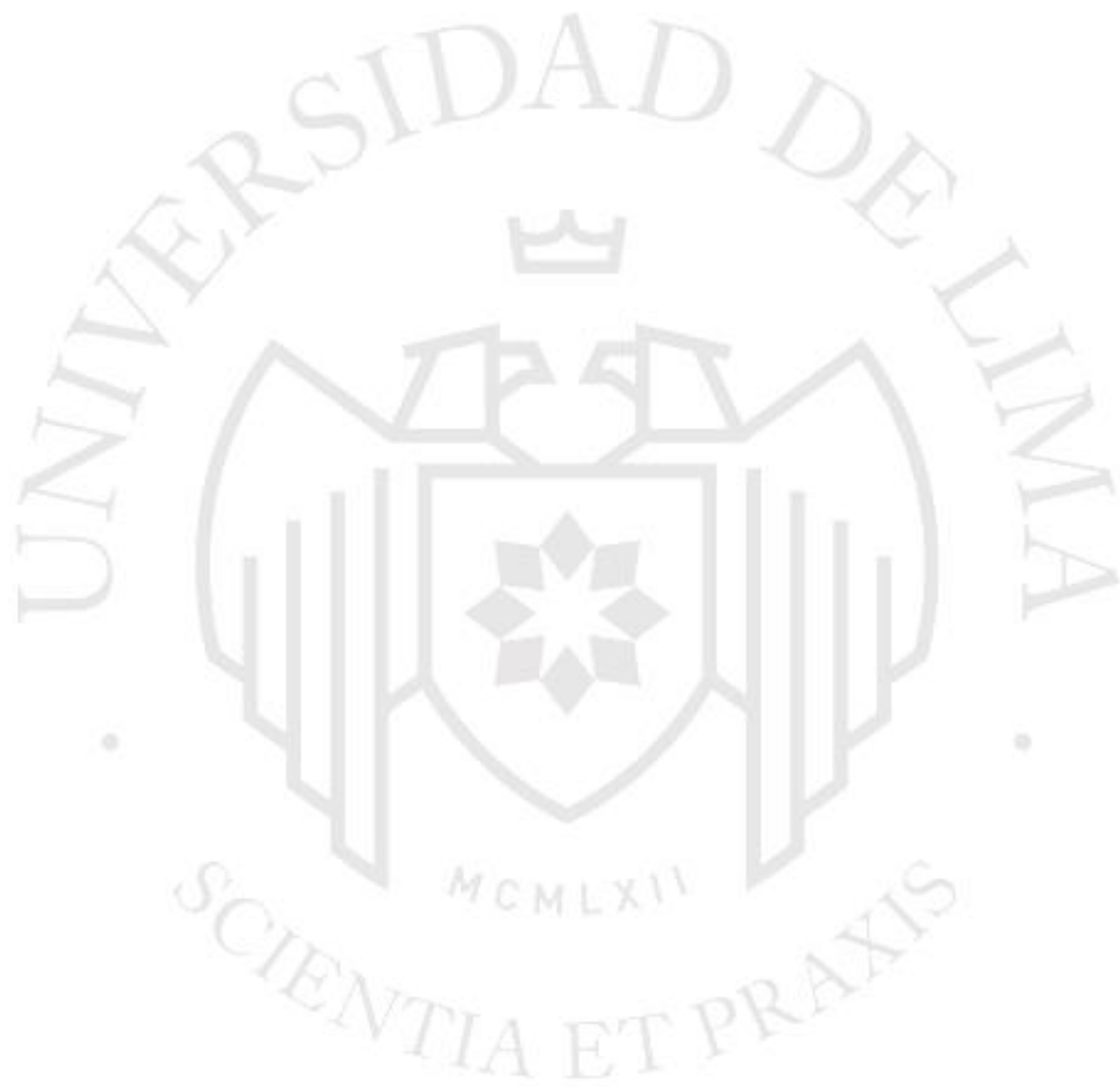


1. ¿Cuál es la postura desde la ética que usted respalda con respecto al uso de los animales para el entretenimien to?
- Lo primero es advertir acerca de qué significa entretenimiento tanto para la ética como para la legislación.

- Las éticas son muy diversas y de mucha tipologizaciones que no las vamos a abordar. Simplemente hay que señalar que un referente esencial son las reglas del bienestar animal ${ }^{8}$ y su reconocimiento legal ${ }^{9}$.

Desde el punto de vista legal nuestra Ley de Protección y Bienestar Animal, Ley $\mathrm{N}^{\circ}$ 30407) define: ESPECTÁCULO DE ENTRETENIMIENTO. Actividad en la cual se obliga a un animal de cualquier especie a realizar acciones en contra de su patrón de comportamiento natural, afectando su integridad física y bienestar, con la finalidad de entretener a un grupo de personas.

Asimismo, prescribe: ARTÍCULO 22. PROHIBICIONES GENERALES se prohíbe toda práctica que pueda atentar contra la protección y el bienestar animal, tales como: (...) B. la utilización de animales en espectáculos de entretenimiento público o privado donde se obligue o condicione a los animales a realizar actividades que no sean compatibles con su comportamiento natural o se afecte su integridad física y bienestar./ Solo se pueden realizar exhibiciones de animales en lugares acondicionados que cumplan medidas de seguridad para prevenir accidentes en las personas y en los animales y autorizados por los sectores competentes, exceptuándose a los especímenes pertenecientes a las especies legalmente protegidas por el estado y los convenios internacionales de los que el país forma parte.
- Lo principal es ser conscientes del tipo de relación que tenemos con los animales, si se dice que se está usando un animal inmediatamente se comete un prejuicio sobre nuestra relación definiéndola como una de tipo utilitaria. Sin embargo, es importante reconocer que nosotros también tenemos relaciones utilitarias con seres humanos, por tanto, lo esencial no es definir que uso, ya que todos en algún momento estamos usando al otro.

- Lo relevante es cómo lo hacemos, reconocer qué tipo de interacción se tiene. Hay diferentes usos. El del circo, el del comercial, el de mi mascota que me sirve para cuidar la casa, o para acompañarme. Hay usos y usos.

Lo que se debe plantear es cuál debería ser nuestra relación con el animal, en la medida que este animal sea tratado con respeto, el uso ya no es utilitario sino considerado, similar al que tenemos con los seres humanos. Y el respeto depende de cómo veamos al animal. Por tanto, es necesario reconocerlo como un ser sintiente con conciencia, pese a que hay gente que considera lo contrario; por consiguiente, incurre en el maltrato, al ser una actitud heredada ya que se ha visto a los animales como inferiores.

8 Por ejemplo, este año se ha establecido "La estrategia mundial de bienestar animal de la OIE" Visión: un mundo en el que el bienestar de los animales se respete, promueva y avance, de manera que complemente la búsqueda de la sanidad animal, el bienestar humano, el desarrollo socioeconómico y la sostenibilidad del medio ambiente. (http://www.oie.int/fileadmin/home/eng/Media Center/docs/pdf/85SG/AW/ES OIE AW Strategy.pdf)

${ }^{9}$ Ley de Protección y Bienestar Animal, Ley № 30407

Definiciones

Bienestar animal. Conjunto de elementos que se refieren a la calidad de vida de los animales, basado en la protección de las especies, respeto a sus hábitats naturales y adaptación a los entornos brindados por el ser humano que les permita desarrollarse y mantener un comportamiento natural y un estado de plena salud física y mental que implica aspectos de sensibilidad referidos principalmente al dolor y al miedo. 


\begin{tabular}{|c|c|c|}
\hline & $\begin{array}{l}\text { En consecuencia, nuestro sistema prohíbe la utilización de animales en } \\
\text { espectáculos de entretenimiento siempre que no se incurra en el detale } \\
\text { mencionado. }\end{array}$ & \\
\hline $\begin{array}{l}2 . \quad \text { ¿Se le } \\
\text { puede } \\
\text { atribuir } \\
\text { derechos } \\
\text { morales a los } \\
\text { animales? } \\
\text { Explique }\end{array}$ & $\begin{array}{l}\text { - Actualmente los sistemas jurídicos no están reconociendo derechos a los } \\
\text { animales, aunque en la teoría muchos admiten que debería ser así } \\
\text { porque tienen un valor inherente en sí mismos, sean humanos o no } \\
\text { humanos. } \\
\text { - Lo que al menos corresponde con realismo es reconocer obligaciones } \\
\text { humanas bienestaristas. }\end{array}$ & $\begin{array}{l}\text { Al ser seres vivos que tienen conciencia, no hay motivo por el cual no } \\
\text { sean merecedores de derechos morales. Sin embargo, cuando recién se } \\
\text { comenzaron a defender los derechos de los animales, los filósofos } \\
\text { argumentaban que se tenía que entender al animal como parte del } \\
\text { contrato social, para extenderle los derechos que tenemos nosotros por su } \\
\text { relación con nosotros, no porque ellos mismos tuviesen un valor } \\
\text { intrínseco, sino que su valor era derivado de su relación con el hombre. } \\
\text { Esto incurría en no reconocer el valor de los animales. } \\
\text { La idea es que hemos vivido una tradición donde el ser humano está en } \\
\text { la cima de la jerarquía y cuando más se distancia es más difícil } \\
\text { considerarlo como un bien intrínseco. } \\
\text { Sin embargo, en la medida en que los derechos de los animales se hacen } \\
\text { depender de la pertenencia del animal al ser humano, ya está viciada la } \\
\text { justicia que se busca al defenderlos. Debe haber un criterio externo al ser } \\
\text { humano que permita reconocerle los derechos que tiene el animal en } \\
\text { cuanto animal, no en cuanto más o menos próximos al ser humano. } \\
\text { Otros criterios deben empezar a tener un peso, desde una visión menos } \\
\text { antropocéntrica y más ecológica, mediante los cuales reconozcamos } \\
\text { derechos morales que eliminen las jerarquías por las que nos } \\
\text { consideramos los únicos agentes morales, con el poder de 'concederles' } \\
\text { esa ciudadanía a los animales y por extensión. } \\
\text { Lo que se debe argumentar es aprender a ver a todos los seres que no son } \\
\text { como nosotros, tomando en cuenta que cada uno tiene un lugar, por }\end{array}$ \\
\hline
\end{tabular}




\begin{tabular}{|c|c|c|}
\hline & & anto, no tenemos el derecho de esclavizar a los animales. \\
\hline $\begin{array}{l}\text { 3. ¿Considera } \\
\text { ético el uso } \\
\text { de animales } \\
\text { para el } \\
\text { entretenimien } \\
\text { to, } \\
\text { especialment } \\
\text { e para el cine } \\
\text { y televisión? }\end{array}$ & $\begin{array}{l}\text { - Siempre que no se atente contra protocolos bienestaristas, sí. } \\
\text { - Hay posturas más extremas que desde el enfoque de la dignidad animal } \\
\text { no lo admiten bajo ninguna manera. }\end{array}$ & $\begin{array}{l}\text { Si es ético o no depende de lo que estemos llamando 'uso'. La } \\
\text { incapacidad de empatía para con los seres vivos, porque no tienen la } \\
\text { misma forma de pensamiento que nosotros es el problema. Es una } \\
\text { cuestión que muchas veces no estamos dispuestos a ver. } \\
\text { Por esto es importante reconocer que cada ser merece respeto y este pasa } \\
\text { a ser objetificado cuando se le deja de reconocer su valor intrínseco } \\
\text { siendo obligado a realizar acciones fuera de su voluntad. Sin embargo, si } \\
\text { un animal es tratado con respeto, permitiéndole hacer cosas que le gusta. }\end{array}$ \\
\hline $\begin{array}{l}4 . \quad \text { ¿Cree } \\
\text { usted que es } \\
\text { importante } \\
\text { que los } \\
\text { animales no } \\
\text { sean } \\
\text { objetificados } \\
\text { para ser parte } \\
\text { de una } \\
\text { producción } \\
\text { audiovisual? } \\
\text { Explique }\end{array}$ & $\begin{array}{l}\text { - Me remito a premisas anteriores en el sentido de respetar criterios y } \\
\text { protocolos bienestaristas. }\end{array}$ & $\begin{array}{l}\text { Exactamente. Cualquier relación con el animal, sobre todo si es } \\
\text { utilitaria, debe considerar al animal no como un objeto sin } \\
\text { subjetividad sino como un particular, un individuo. Igual que con } \\
\text { los seres humanos, independientemente de que hablen otro idioma, } \\
\text { o tengan otro color de piel. Cada animal es como otro individuo } \\
\text { que requiere de un trato justo. } \\
\mathrm{Ni} \text { animales ni seres humanos deberían ser objetificados. La } \\
\text { objetificación es una forma de desconectarse de la responsabilidad } \\
\text { que deberíamos empezar a reconocer para con los animales, como } \\
\text { parte de una conciencia más ecológica de la que nos ha llevado al } \\
\text { desastre global en el que nos encontramos. }\end{array}$ \\
\hline $\begin{array}{l}\text { 5. Existen un } \\
\text { sinfín de } \\
\text { producciones } \\
\text { audiovisuales } \\
\text { desde spots }\end{array}$ & $\begin{array}{l}\text { - No hay que perder una perspectiva transicional para adecuarse a } \\
\text { criterios y protocolos bienestaristas. } \\
\text { - El uso o presencia en los medios y producciones audiovisuales requiere } \\
\text { un proceso transicional hacia un enfoque bienestarista. }\end{array}$ & $\begin{array}{l}\text { No tiene nada de malo que aparezcan que los mostremos como } \\
\text { son, pero someterlos a nuestra necesidad de crear una situación a } \\
\text { su costa muestra esa actitud de la que he estado hablando. }\end{array}$ \\
\hline
\end{tabular}




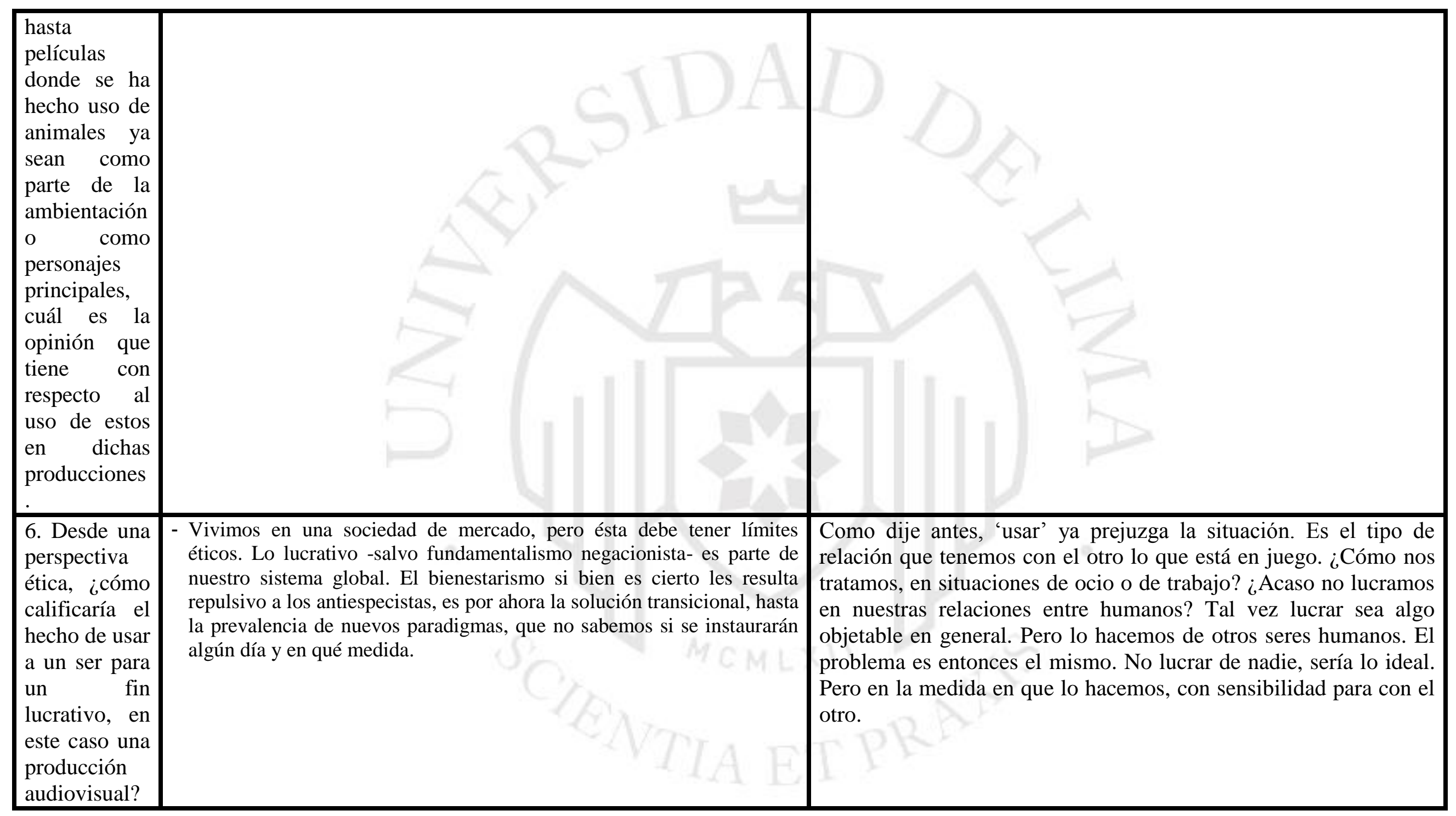




\begin{tabular}{|c|c|c|}
\hline $\begin{array}{l}\text { 7. En cuanto } \\
\text { al punto de } \\
\text { vista legal, } \\
\text { ¿cuál sería el } \\
\text { límite para } \\
\text { defender el } \\
\text { hecho de que } \\
\text { un animal sea } \\
\text { utilizado } \\
\text { como un } \\
\text { objeto y un } \\
\text { bien } \\
\text { intrínseco? }\end{array}$ & $\begin{array}{l}\text { - El límite sería el respeto de las reglas del bienestar animal que ya han } \\
\text { sido reconocidas por nuestra legislación (Ley de Protección y Bienestar } \\
\text { Animal, Ley } \mathrm{N}^{\circ} 30407 \text { ). Sería conveniente en la reglamentación } \\
\text { pendiente afinar estos aspectos para garantizar tales propósitos en el } \\
\text { contexto ético del entretenimiento humando con los animales. }\end{array}$ & $\begin{array}{l}\text { Eso depende de las leyes, y no estoy familiarizado con ellas, pero } \\
\text { por lo que veo estamos aún en la era de las cavernas aquí con } \\
\text { relación al estatuto del animal en la sociedad. Hay escasos locales } \\
\text { 'Pet friendly' en Lima, por ejemplo, y me aventuraría a decir que } \\
\text { solo en San Isidro, Miraflores y Barranco. }\end{array}$ \\
\hline $\begin{array}{l}\text { 8. ¿Cuál es } \\
\text { su opinión } \\
\text { con respecto } \\
\text { al caso de la } \\
\text { película "La } \\
\text { razón de } \\
\text { estar } \\
\text { contigo"? } \\
\text { (https://www } \\
\text {.youtube.com } \\
\text { /watch?v=bS } \\
\text { D56reZHoE } \\
\text { )? }\end{array}$ & $\begin{array}{l}\text { - Deberían existir protocolos bienestaristas en aquellos casos } \\
\text { excepcionales en que se estime que caben actividades de } \\
\text { entretenimiento con animales. Ciertamente en el caso en mención hay } \\
\text { un maltrato animal y una quebrazón a las reglas del bienestar animal. }\end{array}$ & $\begin{array}{l}\text { Una vergüenza para el ser humano poder tratar a un ser obviamente } \\
\text { sensible y consciente de esa manera. Requiere una forma de } \\
\text { inhumanidad que se aproxima a la bestialidad. }\end{array}$ \\
\hline
\end{tabular}

